\title{
Genetic transformation studies and scale up of hairy root culture of Glycyrrhiza glabra in bioreactor
}

\author{
Shakti Mehrotra* \\ Plant Tissue Culture Division \\ Central Institute of Medicinal and Aromatic Plants \\ Lucknow, 226015, India \\ Tel: 9105222733148 Ext. 206 \\ Fax: 9105222361631 \\ E-mail: rajatshaktia@yahoo.com \\ Arun Kumar Kukreja \\ Plant Tissue Culture Division \\ Central Institute of Medicinal and Aromatic Plants \\ Lucknow, 226015, India \\ Tel: 9105222717557 \\ E-mail: akkukreja53@yahoo.com



Financial support: fellowship by Council of Scientific and Industrial Research (CSIR), Government of India to the author Shakti Mehrotra.

Keywords: Agrobacterium, bioreactor, Glycyrrhiza, scale-up, transformed roots.

\author{
Abbreviations: IAA: Indole 3 Acetic Acid \\ PCR: Polymerase Chain Reaction \\ RAPD: Random Amplified Polymorphic DNA technique \\ TF: transformation frequency \\ YMB: Yeast Mannitol Broth
}

The study was undertaken to induce hairy roots in Glycyrrhiza glabra in leaf explants and to optimize the nutritional requirement for its growth kinetics at shake flask and bioreactor level. Pathogenecity of Agrobacterium depends upon transformation ability of strain and age, type, and physiological state of explants. Agrobacterium rhizogenes strain K599 was used to infect leaf explants of $G$. glabra. Explants of different age groups were obtained from 2 to 5 weeks old in vitro grown cultures. Bacterial strain $\mathrm{K599}$ could induce hairy roots in 3 and 4 weeks old leaf explants cultured on $B_{5}$, MS, NB and WP basal semi-solid medium. Leaf explants of 2 and 5 weeks old culture were not responsive to bacterial infection in terms of hairy root induction. Maximum transformation frequency (TF) of tested bacterial strain was $47 \%$ obtained in 3 weeks old explants after 25 days of incubation on MS basal semi solid medium. NB and $B_{5}$ both media composition showed $20 \%$ of transformation frequency after 28 and 38 days respectively. WP medium did not support induction of roots in cultured leaf explants infected with A. rhizogenes strain K599even after 50 days of incubation. Further, when all the four media combinations were tested for root growth it was found that though WP was not responsive for hairy root induction, yet all four basal media supported hairy root growth and a gradual increase in fresh weight biomass was observed with an increase in culture duration. However amongst all, the NB medium composition supported best growth of hairy roots followed by MS, B $_{5}$ and WP media. About 20 times increase in root biomass on fresh weight basis was recorded after 45days of

*Corresponding author 
culture in NB medium. Initial inoculum of roots $(0.18 \mathrm{~g}$ F.wt./ flask) containing $50 \mathrm{ml}$ of liquid culture medium produced $3.59 \mathrm{~g}$ (F. wt.) biomass.

A fast growing hairy root clone G6 was grown in a 5 l capacity mechanically agitated bioreactor provided with a nylon mesh septum. After 30 days of sterile run, $310 \mathrm{~g}$ of root biomass was harvested from the bioreactor culture vessel, recording about 20 times increase over initial inoculum (16.0 g).

The strong co-relation between secondary metabolite production and morphological differentiation gives more impetus to the application of organized cell cultures for large scale production of phytochemicals. The vast potential of hairy root cultures as a stable source of biologically active chemicals (Giri and Narasu, 2000; Kim et al. 2002) has focused the attention of researchers towards the exploitation of this excellent in vitro system through up scaling in novel bioreactors (Kim et al. 2002; Kim et al. 2003) which would provide the best conditions for maximum growth. The main constraints for the commercial exploitation and large scale cultures of hairy roots in bioreactor relate to the operational phases in which several parameters are required to be optimized. One such parameter includes the specific configuration of culture vessel, which is being utilized for growth of tissue. Bioreactor capacity and configuration as well as designing of the culture vessel have been determined according to the type of tissue cultured and this directly influences the physical and chemical parameters of growth (Shanks and Morgan, 1999; Giri and Narasu, 2000; Asplund and Curtis, 2001).

Glycyrrhiza radix, the roots and rhizomes of G. glabra, commonly called as licorice is an important herb. It is a natural source of a triterpenoid saponin Glycyrrhizin. Licorice products are extensively used as a major ingredient of the drugs meant for the treatment of gastric ulcers. Besides, licorice is used in various other drugs due to its anti-inflammatory and anti-tussive properties. In genus Glycyrrhiza few studies related to tissue culture, genetic transformation and flavonoid production through hairy root cultures have been carried out (Ko et al. 1989; Hayashi et al. 1990; Toivonen and Rosenquist, 1995) but their scale up culture at commercial level has not been done so far. In present study a pioneering attempt has been made to optimize few of the various aspects related to induction and up scale culture of genetically transformed roots of $G$. glabra.

\section{MATERIALS AND METHODS}

\section{In vitro establishment of G. glabra cultures}

Aseptic cultures of G. glabra were established by using green and juvenile stem segments of 2-3 cm length along with apical and lateral buds. One year old G. glabra plants growing in earthen pots containing a mixture of sand: soil: farmyard manure (1:1:1) were used as mother source for obtaining explants. These mother plants were maintained under glass house conditions at $60-80 \%$ relative humidity and $25 \pm 5^{\circ} \mathrm{C}$ temperature. These explants were washed thoroughly in a continuous flow of tap water for 2-3 hrs and subsequently surface sterilized with $0.1 \% \mathrm{w} / \mathrm{v}$ mercuric chloride $\left(\mathrm{HgCl}_{2}\right)$ solution for $60-120$ sec. The surface sterilization was followed by rinsing with sterile distilled water. Thoroughly surface sterilized explants were aseptically incubated on MS semi-solid medium supplemented with $1.0 \mathrm{mg} / \mathrm{l}$ IAA. All these aseptic cultures were maintained in culture room under controlled conditions (12:12 h light: dark regime and 3000-4000 lux intensity, $25 \pm 2^{\circ} \mathrm{C}$ incubation temperature and $60 \%$ relative humidity). These aseptic cultures were multiplied by regular subsequent sub-culturing at 3-4 weeks intervals.

\section{Hairy root induction}

\section{Bacterial strain}

Agrobacterium rhizogenes strain K599 was used in the present study. The strain was maintained and cultured on semi-solid Yeast Mannitol Broth (YMB) in plastic Petri dishes (Tarsons, India). The bacterial strain was grown in dark for 48-72 $\mathrm{h}$ at $25 \pm 2^{\circ} \mathrm{C}$ temperature in Petri dishes and were further maintained at $4^{\circ} \mathrm{C}$ in refrigerator. Before using the bacterial strain for any transformation experiment, bacterial suspension culture was prepared by transferring a single cell colony in $10 \mathrm{ml}$ liquid YMB medium in sterile culture tubes and incubated for 24 - 48 hrs on a orbital rotary shaker at $100 \mathrm{rpm}$ at same temperature. The bacterial growth was determined by its optical density measured at $660 \mathrm{~nm}$ using spectrophotometer.

\section{Explant}

In vitro cultures of G. glabra were maintained by routine sub-culturing on MS medium supplemented with $0.1 \mathrm{mg} / \mathrm{l}$ IAA. Leaves excised from 2, 3, 4 and 5 weeks old in vitro raised G. glabra plants were directly used as explants.

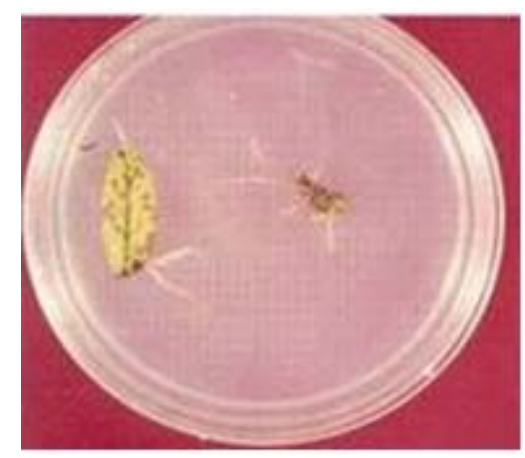

Figure 1. Hairy root induction in leaf explants of $G$. glabra in response of $A$. rhizogenes strain K599. 


\section{Bacterial inoculation}

Leaves obtained from different age group (2-5 weeks old) in vitro grown plants were infected by bacterial strain K599. Explants were pricked with sterile needle dipped in bacterial suspension. Explants pricked with sterile needle dipped in sterile distilled water served as control. All the infected as well as controlled explants were cultured on semi solid $B_{5}$ (Gamborg et al. 1968), MS (Murashige and Skoog, 1962), NB (Nitsch and Nitsch, 1969) and WP (Lloyd and Mc Cown, 1981) basal media dispensed in 90 mm disposable sterile Petri dishes.

After 48 hrs of incubation, the bacterial colonies were visible on the medium. The hairy roots emerging from infected explants were excised and transferred to hormone free fresh medium supplemented with $1 \mathrm{mg} / \mathrm{ml}$ concentration of each antibiotic (sporidex and ampicillin) dispensed in Petri dishes to inhibit the bacterial growth and make hairy root cultures bacteria free. This activity was repeated 3-4 times and during subsequent sub-culturing of hairy roots the antibiotic levels were gradually reduced until the explants were free of bacterial infection and growth of bacteria on medium surface was not visible.

\section{Determination of transformation frequency}

Infected leaf explants were cultured on hormone free MS basal medium and response of these explants to bacterial infections in terms of the hairy root emergence was observed. The TF was determined as follows:

$$
\mathrm{TF}=\frac{\text { Number of pricks showing hairy root emergence }}{\text { Total no. of pricks }} 100
$$

Table 1. Growth performance of transformed roots in different basal media compositions.

\begin{tabular}{|c|c|c|}
\hline \multirow{2}{*}{ Culture period (days) } & MS medium & NB medium \\
\cline { 2 - 3 } & F. wt (g) & F. wt (g) \\
\hline 15 & $0.532^{\star} \pm 0.06^{\star \star}$ & $0.806 \pm 0.05$ \\
$1.33 \pm 0.08$ & $2.22 \pm 0.06$ \\
30 & $2.63 \pm 0.10$ & $3.59 \pm 0.15$ \\
65 & $2.56 \pm 0.32$ & $3.53 \pm 0.20$ \\
\hline 60 & B5 medium & WP medium \\
\hline Culture period (days) & $0.676 \pm 0.04$ & $0.352 \pm 0.07$ \\
15 & $1.71 \pm 0.03$ & $1.28 \pm 0.04$ \\
30 & $2.83 \pm 0.05$ & $1.51 \pm 0.05$ \\
45 & $2.89 \pm 0.05$ & $1.55 \pm 0.03$ \\
\hline 60 & & \\
\hline
\end{tabular}

Initial inoculum of roots $0.18 \mathrm{~g}$ (F.wt)

* Average of five replicates

** Standard error

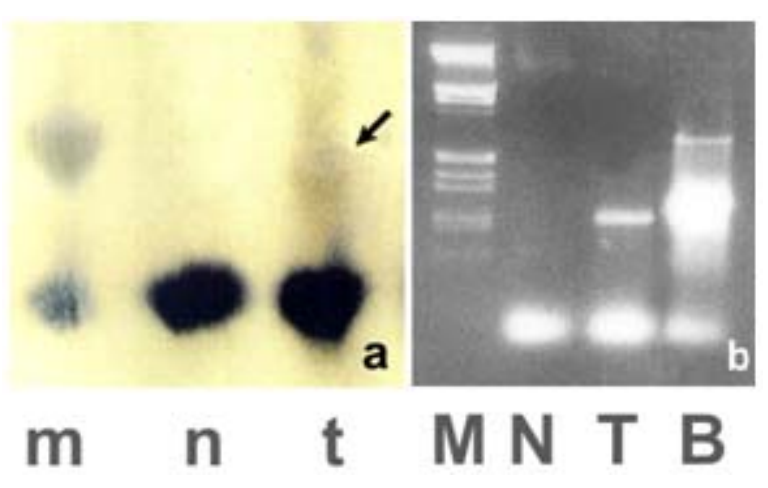

Figure 2. Confirmation of transformed nature of roots. Opine analysis (a) m: standard mannopine, n: non transformed roots, t: transformed roots. RAPD profile (b) Lane M: marker DNA, Lane $\mathrm{N}$ : DNA from non transformed roots, Lane T: DNA from transformed roots and Lane B: DNA from bacterial origin.

\section{Confirmation of transformed nature of hairy roots}

To confirm the transformed nature and the presence of $\mathrm{Ri}$ T-DNA in hairy roots emerging from the pricked sites of explants, both opine analysis (Morgan et al. 1987) and PCR analysis were performed. In opine analysis the homogenous solution of root tissue was spotted on chromatographic paper along with aqueous solution of mannopine which served as standard. For PCR analysis DNA was extracted from non-transformed roots as a control and hairy roots using cetyltrimethyl ammonium bromide (CTAB) method (Khanuja et al. 1999). Primers (5'GGAATTAGCCGGACTAAACG3' and 5' CCGGCGTGGAAATGAATCG3') for detecting rol A gene were used. Total isolated DNA from transformed roots was subjected to restriction digestion with ECO RI and then was assessed by PCR for asserting the presence of T-DNA of bacterial plasmid. The PCR reactions were carried out as per following experimental conditions: initial denaturation at $94^{\circ} \mathrm{C}$ for $1 \mathrm{~min}$, annealing at $50^{\circ} \mathrm{C}$ for $1 \mathrm{~min}$ and extension for $2 \mathrm{~min}$ at $72^{\circ} \mathrm{C}$ for the first cycle which was followed by 35 successive cycles under identical conditions. For further band amplification the PCR reactions were also carried out at three distinctive annealing temperatures i.e. 55,60 and $65^{\circ} \mathrm{C}$.

\section{Optimization of culture medium}

To optimize the suitable culture medium for growth and maintenance hairy roots were cultured in full strength MS, $\mathrm{NB}, \mathrm{B}_{5}$ and WP basal medium containing additional vitamins in the form of RT vitamins of revised tobacco medium (Khanna and Staba, 1968) dispensed in $250 \mathrm{ml}$ Erlenmeyer flasks having $50 \mathrm{ml}$ of medium. No phytohormone was supplemented to any of the above medium. The cultures were kept on a rotary shaker at the speed of $75 \mathrm{rpm}$ and incubated at $25 \pm 2^{\circ} \mathrm{C}$ temperature. The growth kinetics of the roots was observed periodically 
after every 15 days interval from the day of inoculation up to $60^{\text {th }}$ day of culture. The data was recorded as mean of five replicates of a hairy root clone G6 after each culture duration.

\section{Scale up of hairy root culture in bioreactor}

An attempt was made to scale up the fast growing root clone of G. glabra in a bench top, air sparged and mechanically agitated bioreactor of $5 \mathrm{l}$ capacity (model Bio flow 3000, M/s New Brunswick Scientific, USA). This air sparged top driven system had mechanical agitation through marine blade impeller. A thick glass culture vessel with removable baffle assembly consisted of different probes including dissolved oxygen (DO), $\mathrm{pH}$ and temperature probes to control and optimize various culture conditions. The glass culture vessel rests on a double walled stainless steel base through which cold water circulates and maintains the temperature of culture medium. To minimize the medium evaporation during culture, an exhaust gas condenser was provided to the unit. Refrigerated water $4^{\circ} \mathrm{C}$ was circulated through double walled stainless steel condenser with the help of a refrigerated water bath circulator. All the parts of the reactor were thoroughly washed and then surface sterilized with ethyl alcohol prior to assembling the unit and lubricated with silicon grease to make the unit airtight. $4 \mathrm{l}$ of NB medium supplemented with RT vitamins was employed for the experiment. During the experiment, an autoclavable nylon mesh (pore size $200 \mu \mathrm{m}$ ) was tightened just beneath the medium surface so that inoculum roots as well growing roots do not sink to the bottom or get submerged in the medium but remain floating with the support of mesh during the growth phase. Further the mesh

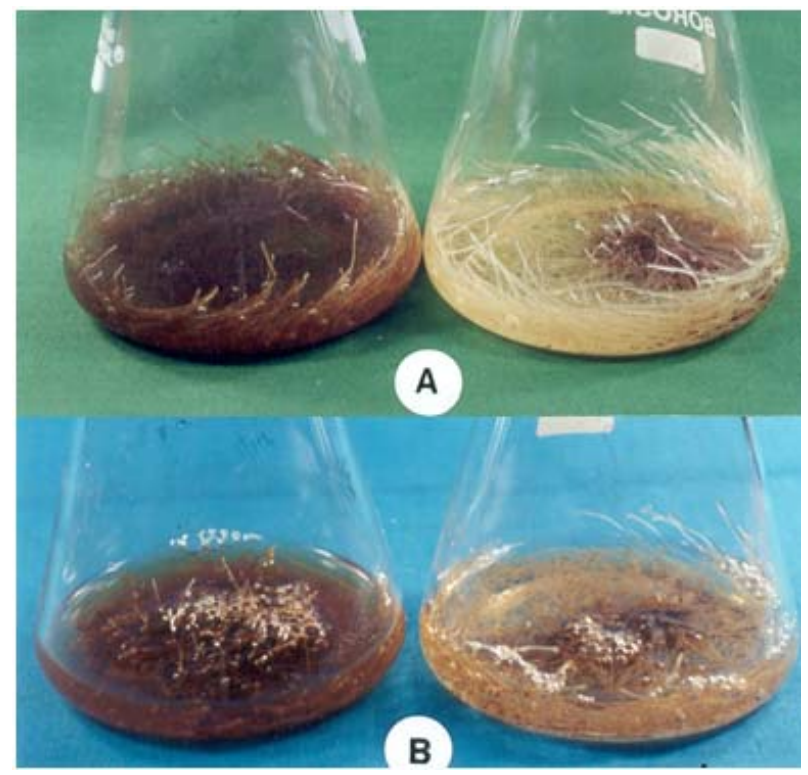

Figure 3. Agrobacterium rhizogenes mediated transformed roots of Glycyrrhiza glabra cultured in different basal medium. (From left to right) B5 and NB (A); WP and MS (B). also provides anchorage surface to the roots. The mesh septum divided the entire vessel into lower and upper compartments. There was a single sparger and a marine impeller in central shaft of the lower vessel compartment for aeration and proper mixing of medium. Thus, septum also protected the cultured tissue mass from shear stress created by agitator. The influent air was passed within the medium through hydrophobic membrane filter (Whatman USA; $0.22 \mu$ ) through sparger.

Sterile culture vessel was inoculated under aseptic condition. Hairy root clone G6 was used for scale up and 16 g (F.wt) of hairy root clone G6 was inoculated. Simultaneously, the same hairy root clone and untransformed (normal) roots ( $0.18 \mathrm{~g}$ ) were also inoculated in $250 \mathrm{ml}$ conical Erlenmeyer flasks containing $50 \mathrm{ml} /$ flask similar culture medium. The experiment duration was 30 days and cultures were incubated at $25 \pm 2^{\circ} \mathrm{C}$ temperature.

\section{Experimental design and statistical analysis:}

The experiments related to TF were performed in five replicates and repeated three times. The mean, standard error and one way ANOVA were calculated. No significant difference (at $\mathrm{P}=0.05$ ) was observed in results.

\section{RESULTS AND DISCUSSION}

\section{Induction and emergence of hairy roots}

A. rhizogenes strain K599 could induce hairy root formation in $47 \%$ excised leaf explants. The time period required for hairy root induction and frequency of transformation varied with respect to the age of explants. Leaf explants obtained from 3 and 4 weeks old in vitro cultures were only the responsive explants (Figure 1) and exhibited 46.6 and $35.0 \%$ TF after 25 and 28 days of bacterial infection respectively. Young leaf explants showed higher TF (47\%) which decreased with an increase in explants age. A number of previous studies showed that type and age of explant have a great influence on hairy root induction since age of explant is a major factor that alters the physiological properties of the cell (Dupre et al. 2000). A strong correlation between TF and the age of wheat donor plants was observed when two different varieties of wheat were used for transformation with Agrobacterium. The mean TF increased from $0.7 \%$ to $5 \%$ using immature embryo from old and young explants respectively (Pastori et al. 2001). Besides, explant age is also an important factor that affects on further hairy root growth and even in production of transgenic also (Vergauwe et al. 1998). Amongst four different basal media employed in the present study maximum TF frequency (47\%) was recorded after 25 days of culture in leaf explants cultured on MS basal semi-solid medium. NB and $\mathrm{B}_{5}$ media showed $20 \%$ TF after 28 and 38 days respectively. The WP medium could not support hairy root induction in cultured leaf explants even after 50 days of incubation. These observations revealed that culture medium composition 
strongly affects the TF and hairy root induction. These observations are similar to the earlier published reports showing the influence of culture medium combinations on hairy root induction in Physalis minima (Azlan et al. 2002; Kumar et al. 2006). Recently, induction of hairy roots in $G$. glabra and G. pallidiflora has been reported (Asada et al. 1998; $\mathrm{Li}$ et al. 1998; $\mathrm{Li}$ et al. 2001) employing $A$. rhizogenes strains pRi15834, pBI121 (GUS). Unlike the present study, where WP medium was reported to be least responsive nutritional media, amongst others four media tested Asada et al. (1998) could obtained G. glabra hairy roots on WP medium in response to infection with $A$. rhizogenes strain pRi 15834 . Thus, it is clear that TF, hairy root induction and growth is strain specific (Sarma et al. 1997; Zehra et al. 1998) and strongly affected by explants age and media formulation.

The confirmation of transformed nature of hairy roots was done by opine analysis and PCR analysis. The presence of black spot on the chromatographic paper along with standard mannopine rendered the confirmation of transformed nature of hairy roots, whereas non-transformed roots did not show any corresponding spot (Figure 2a). Further, DNA extracted from putative transformed roots demonstrated the product of expected size (approx. $350 \mathrm{bp}$ ), when PCR amplification reaction using rol A primers were viewed on $1.2 \%$ agarose TAE gel stained with ethidium bromide (Figure 2b). No amplification products were obtained using non-transformed G. glabra roots as template DNA. Further, PCR reactions were carried out at three distinctive annealing temperatures i.e. 55,60 and $65^{\circ} \mathrm{C}$ for further amplification. However no further improvement in band amplification was observed by increasing annealing temperatures.

Though WP medium used in the present study was not responsive for hairy root induction, yet all four basal media supported further hairy root growth (Table 1). A gradual increase in fresh weight biomass was observed with an increase in culture duration in all four media compositions. However, amongst all, the NB modified medium composition supported best growth of hairy roots followed by MS, $\mathrm{B}_{5}$ and WP medium (Figure $3 \mathrm{a}$ and Figure $3 \mathrm{~b}$ ). About 20 times increase in root biomass on fresh weight basis was recorded after 45 days of culture. Initial inoculum of roots (0.18 g F.wt. / flask) cultured in $50 \mathrm{ml}$ of liquid culture medium multiplied to 3.59 g (F.wt.) biomass. Increasing the culture period beyond 45 days had no effect on hairy root growth and in fact a very marginal decline in root biomass was observed in all media tested, thus indicating the beginning of stationary phase, which was characterized by browning of roots.

The hairy root clone G6 was cultured in a bench top mechanically agitated stirred tank bioreactor containing $4 \mathrm{l}$ modified NB medium. After 30 days of incubation observations were recorded (Table 2). Initially hairy roots showed slow growth rate in reactor vessel and therefore agitation was not required. Thereafter with increasing culture period, the hairy roots formed a compact root mass on supportive nylon mesh (Figure 4a). This necessitated the mechanical agitation for the efficient mixing of culture medium and more efficient gaseous supply to the culture medium in the form of dissolved oxygen.

During this stretch of culture period, air supply was gradually increased to $1.2 \mathrm{l} / \mathrm{min}$ from the initial rate of 0.2 $\mathrm{l} / \mathrm{min}$. On the other hand, for proper distribution of medium in all directions of the vessel, agitation speed was also increased to $200 \mathrm{rpm}$ from the initial speed of $50 \mathrm{rpm}$. After 30 days of sterile run, $310 \mathrm{~g}$ of root biomass was harvested from the bioreactor culture vessel (Figure $4 \mathrm{~b}$ and Figure 3c). There was about 20 times increase over initial inoculum (16 g). Similarly transformed roots cultured in shake flasks also exhibited about 18 fold increases in root biomass. On the other hand normal roots cultured in shake flasks under identical conditions could record approximately two-fold increase $(0.30 \mathrm{~g})$ in root biomass over the initial inoculum size $(0.18 \mathrm{~g} / 50 \mathrm{ml})$ after culture duration of 30 days. The main constraints for the commercial exploitation of hairy root cultures relates to the operational phase in which several parameters are required to be optimized (Giri and Narasu, 2000). A wide variety of reactor configuration has been utilized for the growth of

Table 2. Growth of hairy root clone $\mathbf{G} 6$ in shake flask and bioreactor.

\begin{tabular}{|c|c|c|c|c|c|c|}
\hline Roots & Culture vessel & $\begin{array}{c}\text { Culture } \\
\text { period }\end{array}$ & $\begin{array}{c}\text { Volume of } \\
\text { media }\end{array}$ & $\begin{array}{c}\text { Initial F. wt } \\
\text { (g) }\end{array}$ & $\begin{array}{c}\text { Final F. wt } \\
\text { (g) }\end{array}$ & $\begin{array}{c}\text { Fold } \\
\text { increase }\end{array}$ \\
\hline Normal roots & $\begin{array}{c}\text { Erlenmeyer } 250 \mathrm{ml} \\
\text { flask }\end{array}$ & 30 days & $50 \mathrm{ml}$ & 0.18 & 0.30 & 1.7 \\
\hline $\begin{array}{c}\text { Hairy roots clone } \\
\text { G6 }\end{array}$ & $\begin{array}{c}\text { Erlenmeyer } 250 \mathrm{ml} \\
\text { flask }\end{array}$ & 30 days & $50 \mathrm{ml}$ & 0.18 & 3.40 & 18 \\
\hline $\begin{array}{c}\text { Hairy roots clone } \\
\text { G6 }\end{array}$ & Bioreactor 5 I capacity & 30 days & $4 \mathrm{I}$ & 16.0 & 310 & 20 \\
\hline
\end{tabular}






Figure 4. G. glabra hairy roots in bioreactor (a) Biomass harvested after 30 day of inoculation (b and $c$ ).

roots ranging from conventional stirred tank to rotating drum fermentors (Choi et al. 2006; Srivastava and Srivastava, 2007). Mechanically agitated fermentors without an immobilization structure have been used but success has been limited due to the problems of shear damage by direct contact with impellers. The limited studies, thus far substantiate the intuition that mechanical agitation can be detrimental for the root growth. Very little has been done to explore such operation conditions, which might be possibly support the growth of roots. A modification of the conventional stirred tank, which has been recently used for root culture, is the inclusion of the support matrix to immobilize the roots. While this modification is simple in form, it introduces large differences in operation. Instead of moving with the flow of medium in the reactor vessel, the roots become stationary and the medium flow takes place through the root matrix. In addition, the immobilized root tissue grows in a manner, which is isolated from the mechanical damage of the impeller. Isolated impeller fermentors have been used in various forms and have resulted in good growth performances. In the present investigation also, a fast growing hairy root clone G6 was cultured in a stirred tank fermentor provided with nylon mesh septum. Septum separated the root tissue from the marine impeller employed in the study. Genetically transformed roots exhibited high growth rates under defined conditions and 20 times increase in root biomass was obtained after 30-day culture duration. Studies on the successful use of isolated impeller have also been reported for the hairy roots of Atropa belladonna (Lee et al. 1999). The studies related to reactor vessel configuration for hairy root growth clearly demonstrated that roots could be grown successfully in modified stirred tank reactors (Kim et al. 2002). For scale up of secondary metabolite production through hairy root cultures, interpretation of various physical and chemical parameters on the growth and metabolite production still require great attention before this technology is ready for commercialization. However, we claim our findings as the pioneer work towards the scale up of G. glabra hairy roots employing bioreactors for high biomass production to meet the industrial requirement.

\section{ACKNOWLEDGEMENTS}

Authors (S.M. and A.K.K.) are thankful to Director, CIMAP, Lucknow for providing facilities to carry out the work.

\section{REFERENCES}

ASADA, Yoshihisa; LI, Wei and YOSHIKAWA, Takafumi. Isoprenylated flavonoids from hairy root cultures of Glycyrrhiza glabra. Phytochemistry, February 1998, vol. 47, no. 3, p. 389-390.

ASPLUND, Patrick T. and CURTIS, Wayne R. Intrinsic oxygen use kinetics of transformed plant root culture. Biotechnology Progress, May-June 2001, vol. 17, no. 3, p. 481-489.

AZLAN, G.J.; MARZIAH, M.; RADZALI, M. and JOHARI, R. Establishment of Physalis minima hairy roots culture for the production of Physalins. Plant Cell, Tissue and Organ Culture, June 2002, vol. 69, no. 3, p. 271-278.

CHOI, Yong E.; YOON, Soo Kim and KEE, Yoeup Paek. Designs of bioreactors for hairy root culture. In: GUPTA, S. Dutta and IBARAKI, Yasuomi eds. Focus on Biotechnology: Plant tissue culture engineering. Springer, Netherlands, 2006, p. 161-172.

DUPRE, Patricia; LACOUX, Jerome; NEUTELINGS, Godfrey; MATTAR-LAURAIN, Dominique; FLINIAUX, Marc Andre; DAVID, Alain and JACQUIN-DUBREUIL, Annie. Genetic transformation of Ginkgo biloba by A. tumefaciens. Physiologia Plantarum, April 2000, vol. 108, no. 4, p. 413-419.

GAMBORG, O.L.; MILLER, R.A. and OJIMA, K. Nutrient requirements of suspension cultures of soybean root cells. Experimental Cell Research, April 1968, vol. 50, no. 1, p. 151-158.

GIRI, Archana and NARASU, Lakshmi M. Transgenic hairy roots: Recent trends and applications. Biotechnology Advances, March 2000, vol. 18, no. 1, p. 1-22.

HAYASHI, Hiroaki; SAKAI, Tsutomu; FUKUI, Hiroshi and TABATA, Mamoru. Formation of soyasaponins in licorice cell suspension cultures. Phytochemistry, 1990, vol. 29, no. 10 , p. 3127-3129.

KHANNA, Pushpa and STABA, John E. Antimicrobials from plant tissue cultures. Lloydia, 1968, vol. 31, no. 2, p. 180-189.

KHANUJA, Suman P. Singh; SHASANY, Ajit K.; DAROKAR, Mahendra P. and KUMAR, Sushil. Rapid 
isolation of DNA from dry and fresh samples of plants producing large amounts of secondary metabolites and essentials oils. Plant Molecular Biology Reporter, 1999, vol. 17, no. 1, p. 74-80.

KIM, Yoo Jeong; WYSLOUZIL, Barbara E. and WEATHERS, Pamela J. Secondary metabolism of hairy root cultures in bioreactors. In vitro Cellular and Developmental Biology-Plant, January 2002, vol. 38, no. 1, p. 1-10.

KIM, Yoo Jeong; WYSLOUZIL, Barbara E. and WEATHERS, Pamela J. Growth dynamics of Artemisia annua hairy roots in three culture systems. Biotechnology and Bioengineering, February 2003, vol. 83, no. 4, p. 428443.

KO, Kyung-Soo; HIROSHI, Noguchi; YUTAKA, Ebizuka and USHIO, Sankawa. Oligoside production by hairy root cultures transformed by $\mathrm{Ri}$ plasmids. Chemical and Pharmaceutical Bulletin, 1989, vol. 37, no. 1, p. 245-248.

KUMAR, Vinod; SHARMA, Ashwani; PRASAD, Bellur Chayapathy Narasimha; GURURAJ, Harishchandra Bhaskar and RAVISHANKAR, Gokare Aswathanarayana. A. rhizogenes mediated genetic transformation resulting in hairy root formation is enhanced by ultrasonication and acetosyringone treatment. Electronic Journal of Biotechnology [online]. 15 July 2006, vol. 9, no. 4 [March 15 2007]. Available from Internet: http://www.ejbiotechnology.info/content/vol9/issue4/full/4/ index.html. ISSN 0717-3458.

LEE, K.-T.; SUZUKI, T.; YAMAKAWA, T.; KODAMA, T.; IGARASHI, Y. and SHIMOMURA, K. Production of tropane alkaloids by transformed root cultures of Atropa belladonna in stirred tank bioreactors with stainless steel net. Plant Cell Reports, March 1999, vol. 18, no. 7-8, p. 567-571.

LI, Wei; ASADA, Yoshihisa and YOSHIKAWA, Takafumi. Antimicrobial flavonoids from Glycyrrhiza glabra hairy root cultures. Planta Medica, December 1998, vol. 64, no. 8, p. 746-747.

LI, Wei; ASADA, Yoshihisa; KOIKE, Kazuo; HIROTANI, Masao; RUI, Hekai; YOSHIKAWA, Takafumi and NIKAIDO, Tamotsu. Flavonoids from Glycyrrhiza pallidiflora hairy root cultures. Phytochemistry, October 2001, vol. 58, no. 4, p. 595-598.

LLOYD, G. and MCCOWN, B. Commercially feasible micropropagation of mountain laurel, Kalmia latifolia by use of shoot tip culture. International Plant Propagation Society Proceedings, 1981, vol. 30, p. 421-427.

MORGAN, A.J.; COX, P.N.; TURNER, D.A.; PEEL, E.; DAVEY, M.R.; GARTLAND, K.M.A. and MULLIGAN, B.J. Transformation of tomato using an Ri plasmid vector. Plant Science, 1987, vol. 49, no. 1, p. 37-49.
MURASHIGE, T. and SKOOG, F. A revised medium for rapid growth and bioassay with tobacco tissue culture. Physiologia Plantarum, 1962, vol. 15, p. 473-497.

NITSCH, J.P. and NITSCH, C. Haploid plants from pollen grains. Science, January 1969, vol. 163, no. 3862, p. 85-87.

PASTORI, Gabriela M.; WILKINSON, Mark D.; STEELE, Sue H.; SPARKS, Caroline A.; JONES, Huw D. and PARRY, Martin A.J. Age dependent transformation frequency in elite wheat varieties. Journal of Experimental Botany, April 2001, vol. 52, no. 357, p. 857-863.

SARMA, Dhiren; KUKREJA, Arun K. and BARUAH, A. Transforming ability of two Agrobacterium rhizogenes strains in Rauvolfia serpentina L. leaves. Indian Journal of Plant Physiology, 1997, vol. 2, no.2, p. 166-168.

SHANKS, Jacqueline V. and MORGAN, John. Plant "hairy root" culture. Current Opinion in Biotechnology, April 1999, vol. 10, no. 2, p. 151-155.

SRIVASTAVA, Smita and SRIVASTAVA, Ashok K. 'Hairy root culture for mass-production of high-value secondary metabolites. Critical Reviews in Biotechnology, January 2007, vol. 27, no. 1, p. 29-43.

TOIVONEN, Leena and ROSENQUIST, Heikki. Establishment and growth characteristics of Glycyrrhiza glabra hairy root cultures. Plant Cell, Tissue and Organ Culture, June 1995, vol. 41, no. 3, p. 249-258.

VERGAUWE, A.; VAN GELDRE, E.; INZE, D.; VAN MONTAGU, M. and VAN DEN EECKHOUT, E. Factors influencing $A$. tumefaciens mediated transformation of Artemisia annua L. Plant Cell Reports, November 1998, vol. 18, no. 1-2, p. 105-110.

ZEHRA, Mehar; BANERJEE, Suchitra; NAQVI, Ali Arif and KUMAR, Sushil. Variation in the growth and alkaloid production capability of the hairy roots of Hyoscyamus albus, H. muticus and their somatic hybrid. Plant Science, August 1998, vol. 136, no. 1, p. 93-99. 